\title{
A IMIGRAÇÃO, A ETNOGRAFIA E A ÉTICA
}

\author{
Rachael Anneliese Radhay
}

\begin{abstract}
The relation between discourse and power in Brazilian immigration is complex. There is the public sphere with the State's immigration officials. There are also migrants in the intricacies of their worlds. Discourse and power refer to hierarchies of contexts and relations in which multiple truths are constructed vis à vis immigration. There is marked discrimination in the representation and evaluation of immigrants. Those with high investments or specialist knowledge are welcome whilst those who are socially underprivileged are valueless. All these issues can be considered through ethnography. However, delving ethnographically into the complexities of immigration stirs up ethical issues.
\end{abstract}

Key words: immigration, ethnography, ethics, discourse.

A teia da imigração não pode ser restrita a um tipo de discurso ou identidade. É sim como uma rede complexa, que pode ser entendida apenas com uma etnografia extensa e que busca entender as várias vozes embutidas no discurso. Há ângulos e dimensões distintos - vozes em conflito; vozes apagadas; vozes em acordo. No mundo da imigração, existem várias questões: a soberania, o nacionalismo, a segurança, fatores econômicos, o mercado de trabalho e a proteção da mão-de-obra local. Nesse sentido, a imigração não se trata apenas do fluxo de seres humanos de um lugar a outro; talvez, se fosse assim, o fenômeno imigratório seria menos complexo. Portanto, escrever sobre a imigração não é um processo simples - existem múltiplas narrativas. Quem são os protagonistas? De quem são as vozes? Como se relacionam? Há inúmeras histórias e experiências a serem contadas e ouvidas - depoimentos individuais e coletivos. Como e por que essas experiências são relatadas depende de quem está relatando e do(a) interlocutor(a). Além do mais, essas experiências são influenciadas pela maneira pela qual a narrativa imigratória é ligada a outras narrativas.

Por um lado, a narrativa imigratória faz parte da narrativa do Estadonação ${ }^{1}$ - como se constrói ou se narra como nação; por outro lado, a imi-

1. O Estado-nação se define da seguinte maneira: ““Estado” é um conceito definido juridicamente: do ponto de vista objetivo, refere-se a um poder estatal soberano, tanto interna quanto externamente; quanto ao espaço, refere-se a uma área claramente de- 
gração faz parte de movimentos imigratórios coletivos e as suas histórias; ao mesmo tempo, a narrativa imigratória é pessoal - faz parte da história de vida. A narrativa imigratória possui, portanto 'focos em fluxo'. Existem simetrias e assimetrias; pontos em comum e divergências. Além de haver vários protagonistas, há influências externas e mudanças (a 'globalização', fatores econômicos, por exemplo), de forma que a narrativa parece transitória. Sempre há algo a mais para contar, as leis são modificadas, os (as) imigrantes mudam de um lugar a outro. Além disso, a narrativa da imigração não remete simplesmente a uma história convencional, pois remete à grande narrativa da nação ${ }^{2}$. Por exemplo, a lei de imigração é, interdiscursivamente, uma narrativa ${ }^{3}$, pois contribui para construir a perspectiva do Estado-nação sobre a imigração e também constitui a própria história do Estado-nação: uma comunidade construída ${ }^{4}$. Ao mesmo tempo, os (as) imigrantes possuem as suas próprias histórias - os seus mundos - pessoas que mudaram de um lugar a outro devido a circunstâncias distintas; pessoas em busca de uma vida melhor ou oportunidades de emprego; refugiados fugindo da perseguição política, guerras ou até desastres naturais; aventureiros, casamentos, interesses culturais. Portanto, a imigração é motivada por escolhas, decisões tomadas voluntariamente ou 'impostas' devido a fatores externos como conflitos políticos, desastres naturais, falta de oportunidades ou de emprego.

Entender a narrativa da imigração é um processo complexo. Além de haver vários protagonistas, há influências externas e mudanças (a 'globali-

limitada, o território do Estado. Para além da fixação jurídica, no entanto, "nação" também tem o significado de uma comunidade política marcada por uma ascendência comum, ao menos por uma língua, cultura e história em comum .....a origem nacional, que era atribuída por outros, esteve associada desde o início como a delimitação negativa entre o próprio e o estrangeiro" (Habermas, 2002: 129-130; 132).

2. A narrativa em pesquisas sobre imigração baseia-se geralmente nas histórias e nas experiências de imigrantes, porém, a imigração, mediante leis, resoluções e depoimentos de representantes do governo contribui para fortalecer a história/a narrativa da nação. O Estado-nação constrói a sua história, a sua imagem, a imigração faz parte dessa narrativa, pois mediante a política imigratória, o Estado-nação se constrói como protetor da soberania nacional.

3. As leis são interdiscursivas, pois nelas é embutida a história do Estado-nação como protetor dos interesses nacionais. A elaboração de leis e de resoluções não se baseia apenas na política do Estado-nação no tocante à imigração, mas embutida nesse processo está não é a narrativa de como o Estado-nação se constrói.

4. Bauman escreve sobre a busca por uma comunidade segura do outro; de certa forma, o discurso imigratório do Estado-nação procura estabelecer uma comunidade em que todos(as) são bem tratados(as) (2003). 
zação', fatores econômicos, por exemplo), de forma que a narrativa parece transitória. Sempre há algo a mais para contar, as leis são modificadas, os (as) imigrantes mudam de um lugar a outro. Além disso, a narrativa da imigração não remete simplesmente a uma história convencional, pois remete à grande narrativa da nação ${ }^{5}$. Por exemplo, a lei de imigração é, interdiscursivamente, uma narrativa ${ }^{6}$, pois contribui para construir a perspectiva do Estado-nação sobre a imigração e também constitui a própria história do Estado-nação: uma comunidade construída ${ }^{7}$. Ao mesmo tempo, os (as) imigrantes possuem as suas próprias histórias - os seus mundos - pessoas que mudaram de um lugar a outro devido a circunstâncias distintas; pessoas em busca de uma vida melhor ou oportunidades de emprego; refugiados fugindo da perseguição política, guerras ou até desastres naturais; aventureiros, casamentos, interesses culturais. Portanto, a imigração é motivada por escolhas, decisões tomadas voluntariamente ou 'impostas' devido a fatores externos como conflitos políticos, desastres naturais, falta de oportunidades ou de emprego.

Não obstante, a imigração, conforme mencionado anteriormente, não corresponde apenas ao movimento de povos de um lugar a outro, mas também remete a fronteiras, territórios, nações, soberania e controle. As relações de po$\operatorname{der}^{8}$ são implícitas à imigração. Desse modo, a imigração como narrativa é construída de hierarquias de narrativas ou relatos: uma teia complexa ou um pastiche de discursos, construído por estratégias e argumentos, e regido pelo poder e pela hegemonia9 ${ }^{9}$ Entender esse pastiche é um desafio: entender como o poder e o

5. A narrativa em pesquisas sobre imigração baseia-se geralmente nas histórias e nas experiências de imigrantes, porém, a imigração, mediante leis, resoluções e depoimentos de representantes do governo contribui para fortalecer a história/a narrativa da nação. O Estado-nação constrói a sua história, a sua imagem, a imigração faz parte dessa narrativa, pois mediante a política imigratória, o Estado-nação se constrói como protetor da soberania nacional.

6. As leis são interdiscursivas, pois nelas é embutida a história do Estado-nação como protetor dos interesses nacionais. A elaboração de leis e de resoluções não se baseia apenas na política do Estado-nação no tocante à imigração, mas embutida nesse processo está a narrativa de como o Estado-nação se constrói.

7. Bauman escreve sobre a busca por uma comunidade segura do outro; de certa forma, o discurso imigratório do Estado-nação procura estabelecer uma comunidade em que todos(as) são bem tratados(as) (2003).

8. O mundo da imigração não é um espaço neutro ou simétrico, porque é composto de diversas relações hierárquicas, em que há representantes do governo, agentes policiais, imigrantes altamente qualificados, imigrantes não-documentados; são os representantes do governo que detêm a voz principal.

9. "A hegemonia refere-se à naturalização de relações de poder como sendo dominan- 
discurso operam e são constituídos na imigração significa desvendar o espaço subjacente à imigração. Esse espaço não pode ser simplificado, não pode ser definido como uma mera dicotomia entre 'nós' e 'eles', pois os grupos de 'nós' e 'eles' são compostos de subgrupos, em que pode haver discursos em conflito.

Nesse sentido, os dados deste estudo foram coletados de vários contextos e fontes: documentos e leis, entrevistas com representantes do Estado, observação no guichê de atendimento ao estrangeiro da Polícia Federal de Brasília, entrevistas com imigrantes (documentados e não-documentados), observação em um albergue de migrantes em São Paulo, observação da reunião do Conselho Nacional de Imigração, conversas informais e participação na página da Associação Nacional de Estrangeiros e Imigrantes do Brasil. Além disso, há conversas de corredor e notas de campo. Todos esses dados provêm de diversos contextos, mas são todos interligados, apresentando questões de poder e controle.

Porém, a imigração não se trata apenas do discurso institucional-imigratório e da identidade nacional coletiva, trata-se de mundos pessoais - as experiências do dia-a-dia de imigrantes. Ao pedir aos(às) imigrantes para falar sobre suas experiências imigratórias, temos narrativas. Eles/elas falam de seus planos e projetos e em alguns casos contam as suas experiências no processo de conseguir o visto. Outros(as) têm uma tendência de omitir essas experiências, talvez estejam sendo diplomáticos, talvez estejam apenas preocupados com seguir adiante ou tenham medo de dizer algo desfavorável sobre o sistema imigratório. De certa forma, esses relatos dependem do contexto, e também remetem a questões de confiança e confidências na etnografia - até que ponto podem confiar no(a) pesquisador(a)?

Na leitura das correspondências entre imigrantes, participantes na página eletrônica da Associação Nacional de Estrangeiros e Imigrantes do Brasil, cabe notar a franqueza com a qual as dificuldades e as experiências referentes a processos de visto ou outras questões burocráticas são consideradas. Há também uma questão de segurança do grupo e de 'pertencimento', considerando-se os (as) imigrantes sem documentos; por exemplo, os costureiros bolivianos, que não conseguem nem participar do site, devido às condições de vida em que trabalham, mais de doze horas por dia.

Este estudo propõe integrar a abordagem da etnografia a questões éticas. A etnografia, ora como estratégia na coleta de dados, ora como gênero discursivo (uma narrativa) (Chouliaraki, 1994; Josselson \& Lieblich, 1993; Thomas, 1993; van Maanen, 1988) não pretende criar ou reforçar estereótipos. Ao contrário, procura fomentar reflexões sobre a ambivalência pós-moderna

tes" (Chouliaraki \& Fairclough, 1999: 24). 
(Fairclough, 2003; Giddens, 2001; Bhabha, 1994), focalizando especificamente o vínculo entre o Estado-nação e questões de imigração.

\section{A etnografia e a ética}

Tendo em vista as múltiplas faces desta pesquisa, torna-se imprescindível entender o(s) mundo(s) da coleta de dados, pois a etnografia acabada não reflete o engajamento do(a) pesquisador(a) nesses mundos. Esse engajamento acarreta questões éticas, pois a etnografia não se trata apenas de escrever um relato da coleta de dados, mas significa a intersubjetividade - um encontro de múltiplas vozes. $\mathrm{O}$ processo de tecer as vozes da pesquisa envolve escolhas, bem como um diálogo delicado durante e após a coleta de dados (Henry, 2003; Drury \& Stott, 20010. Sherif, 2001; Roberts, 2000). Não é uma mera questão de realizar entrevistas e/ ou gravações para obter dados; não é automático assim: "O etnográfico exige que o(a) observador(a) ele/ela mesma faça parte da observação, e isso requer que o campo de conhecimento - o fato social total - não deve ser apropriado de fora como uma coisa, mas como uma coisa que detém em si o entendimento subjetivo do endógeno?" (Bhabha, 1994: 150). Esse entendimento subjetivo provoca, por sua vez, outras questões relacionadas ao engajamento do(a) pesquisador(a) com as crenças positivistas de neutralidade e de distanciamento. Desse modo, o primeiro contato com o mundo da pesquisa suscita várias questões:

- Como conseguir contatos?

- Como conquistar a confiança dos/as participantes?

- Como discernir entre a verdade e a 'não'-verdade?

- Como distinguir entre a voz da instituição e a voz do sujeito?

- Até que ponto os participantes estão dizendo apenas o que eu 'quero' ouvir?

- Como sou estrangeira, até que ponto esse fator pode influenciar a participação/os depoimentos dos/as participantes?

Mesmo assim, o mundo da pesquisa vai muito além de questionamentos feitos no início do trabalho de campo: existem outras complexidades que sur-

10. Drury \& Stott escrevem: "Cada tipo de metodologia envolve a interpretação por parte do(a) pesquisador(a), e a interpretação pressupõe um sujeito interpretador. Em outras palavras, a comunidade científica não pode escapar da subjetividade uma vez que nós somos sempre sujeitos irredutíveis (Drury, 1994). A subjetividade e a objetividade não são campos distintos, mas se constituem" (2001: 63). 
gem no decorrer do trabalho. Em outras palavras, o trabalho de campo, por ser um encontro de diversas vozes, adquire uma vida própria, torna-se uma rede em que o(a) pesquisador(a) não está sempre em controle do ambiente. Leif e Cytrynbaum comentam:

Os espaços relacionais da pesquisa são aqueles momentos quando os propósitos originalmente fixados na coleta de dados estabelecida tornam-se periféricos e as dinâmicas relacionais da pesquisa transforma-se no foco (2003: 252).

Em várias ocasiões, terminei sendo entrevistada pelos próprios pesquisados, tanto os estrangeiros quanto os burocratas: nota-se a curiosidade de saber da minha vida. Seguem dois exemplos dessa curiosidade. O primeiro ocorreu em São Paulo durante o período de pesquisa na Casa do Migrante; o segundo faz referência ao primeiro encontro com um dos membros do Conselho Nacional de Imigração:

No dia seguinte, notei-os mais reservados, particularmente $\mathrm{G}$ comentou que estavam desconfiados. Peguei os papéis de J para comprovar o que fazia. $\mathrm{G}$ ficou fazendo perguntas sobre a minha vida, namorados etc,.... bom tinha que responder (nota de campo: 18/1/05); ela me entrevistou do mesmo jeito como a entrevistei. Isto é algo interessante na pesquisa etnográfica, 'desarmando-se', a transparência, ela perguntou se eu tinha o visto permanente. (Nota de campo: 21/2/05)

Desse modo, o poder faz interface com o gênero social e a nacionalidade. Por exemplo, a sensação de dependência é um assunto bastante pertinente nesta pesquisa. Em São Paulo, durante a visita à Casa do Migrante, tinha de abrir mão (até certo ponto) da minha independência devido à questão de segurança - não conhecia bem a cidade e não me sentia à vontade ao andar até o metrô, sozinha, à noite, então em muitas ocasiões, os próprios migrantes (homens) me acompanhavam até a estação, reconheciam que, no final de contas, era estrangeira igual a eles. Tive aqui a experiência de ter de enfrentar a minha própria vulnerabilidade como mulher/estrangeira em uma cidade estranha, é uma vulnerabilidade que não pode ser apagada, subjaz ao trabalho de campo. Como ser pesquisadora quando me sinto como se estivesse pisando em ovos; os locais perigosos de São Paulo, participantes que são principalmente homens desconhecidos e carentes (Nilan, 2002). Mesmo assim, é essa própria vulnerabilidade que marca o vínculo com os(as) participantes. Ela gera a interação e a confiança dos(as) participantes, que me contam suas ansiedades: estabelece um laço com eles/elas ${ }^{11}$.

11. " $\mathrm{O}$ (a) pesquisador(a) consciente e inconscientemente busca o apoio no campo: os 
Bueno, después era la hora de la cena, la cola, sacamos fotos. Creo que yo me siento más conmovida. José me dio un regalo, habló también de la chica. Comentó sobre las chicas que 'les alcanzan' son aquellas que tienen 'brinco na barriga'. É engraçado o africano (Martin), sei que tem problemas mentais, mas mesmo assim, o comentário não deixa de ter validade, ele é discriminado porque não tem como conseguir uma boa mulher. $\mathrm{O}$ outro africano também (Jean) estava preocupado sobre a questão de família: Como será a sua vida? Sacaron fotos, fueron conmigo hasta el metro. Pablito habló nuevamente. São homens carentes. A questão de gênero não é sempre com as mulheres. Estrangeiros carentes. (Nota de campo da última visita à Casa do Migrante, 27/1/2005.)

A etnografia não é alheia à questão de gênero no campo: influencia o entrosamento com os(as) participantes: ao reconhecer a minha própria vulnerabilidade e ao aceitar a minha identidade como mulher estrangeira-imigrante (e não necessariamente como 'pesquisadora independente e feminista'), a aproximação aos(às) participantes se torna viável: "O papel de mascote é adotado não muito voluntariamente como necessidade, quando o(a) pesquisador(a) percebe que pode alcançar as suas metas de pesquisa mais facilmente se abandonar a sua preciosa identidade feminista" (Adams, 1999: 337).

Em Brasília, a sensação de falta de poder surge nos primeiros encontros com os membros do governo: ocupam altos cargos, e além de ser pesquisadora, também sou estrangeira. Dessa forma, o mundo da pesquisa não é alheio a minha própria subjetividade: subjacente à coleta de dados, há uma corrente de subjetividades cruzadas e o poder permeia essa corrente, em que a pesquisadora não incorpora sempre a voz dominante:

Embora o(a) pesquisador(a) sempre tenha a última palavra como autor das descobertas da pesquisa, no decorrer da pesquisa, o poder oscila entre o(a) pesquisador(a) e os seus informantes, às vezes posicionando o(a) pesquisador(a) em uma situação de estar sem poder (Adams, 1999: 332).

Dito de outra forma, a pesquisa de campo não significa uma relação binária entre pesquisador(a) e participante, conforme escreve Dimitriadis: "A pesquisa qualitativa é atualmente uma prática bastante desnivelada do que é sugerido normalmente por uma relação binária" (2001: 595). O engajamento com o outro não é simples nem dicotômico.

etnógrafos se orgulham dos relacionamentos construídos durante o trabalho de campo, em contraste com o caráter superficial de enquetes e questionários. Não há nada falsificado nisso; esses relacionamentos freqüentemente fornecem o apoio emocional necessário para o(a) pesquisador(a) e criam um verdadeiro vínculo com os anfitriões ou informantes" (Springwood \& King, 2001: 404). 
A título de exemplo, durante a entrevista com o representante do $\mathrm{Mi}$ nistério do Trabalho e Emprego, minha opinião foi solicitada sobre a questão de imigração no Brasil, com referência específica à situação dos (as) imigrantes bolivianos não-documentados em São Paulo. Tinha deixado perceber minha preocupação com a situação desse grupo ("queria saber o que eu sabia/ pensava" - Nota de campo: 22/2/05), e terminei sendo convidada a trabalhar como voluntária na elaboração de uma 'cartilha' do governo voltada a essa comunidade. Essa oportunidade levou a outros contatos, assim ressaltando os questionamentos de Leif \& Cytrynbaum:

Como interagiram o etnógrafo e os sujeitos nas interações do dia-adia no campo? De quem falaram? Como é que essas relações afetaram a maneira em que a pesquisa evoluiu? Quais escolhas representacionais foram feitas pelo(a) pesquisador(a) devido a essa cumplicidade? Como é que essas dinâmicas de inter-relacionamento levaram o(a) pesquisador(a) a outros locais? (2003: 259).

Em suma, o exemplo de colaboração e os questionamentos de Leif \& Cytrynbaum sugerem que a etnografia não existe sem o engajamento, sem a interação com os/as participantes (Berger, 2001).

A colaboração contribui para estabelecer a transparência na pesquisa, significando uma prática com base na ética. Além disso, possibilita trabalhar sobre, com, e para o(a) pesquisado(a) para que haja a transformação social fortalecedora (Cameron et al., 1999:153; Gieve \& Magalhães, 1994). Portanto, a oportunidade de trabalhar com um grupo do Ministério do Trabalho e Emprego na elaboração de uma cartilha para a comunidade boliviana, conforme mencionado antes, significou uma forma de colaboração.

Contudo, a colaboração e o engajamento no campo trazem à tona não apenas questões de diálogo e de polifonia (Chouliaraki, 1994), mas ressaltam também o conflito entre a distância e o engajamento na pesquisa. Como posso escrever sobre imigrantes às margens da sociedade brasileira sem tentar ajudá-los? Como posso entrevistar os funcionários da imigração sem levantar a condição dos bolivianos em situação de trabalho semi-escravo? Como posso usar as palavras dos burocratas contra eles, quando eles mesmos parecem tão dispostos a colaborar com a pesquisa? Como posso revelar histórias de imigrantes não-documentados conquistadas pela confiança e pela amizade sem quebrar a confidencialidade? Todas essas perguntas reiteram meu dilema, na medida em que procuro manter a confidencialidade e ao mesmo tempo desenvolver a agenciação ${ }^{12}$ : "Se os (as) pesquisadores(as) consideram-se ativistas

12. Note-se: A agenciação difere de 'agência' como elemento lingüístico-textual. 
políticos assim como pesquisadores(as), devem resolver outro dilema: devem conciliar as responsabilidades como pesquisadores(as)/protetores(as) e ativistas/expositores(as)" (Baez, 2002: 5).

A relação entre confidencialidade e agenciação é contraditória, representando dois mundos paralelos e, ao mesmo tempo, intimamente ligados. (Ver Quadro 1).

Quadro 1 - Etnografia e ética

\begin{tabular}{|c|c|}
\hline Confidencialidade & Agenciação* \\
\hline $\begin{array}{l}\text { Significa o estabelecimento de um } \\
\text { vínculo de confiança entre o(a) } \\
\text { participante e o (a) pesquisador(a) } \\
\text { para que o primeiro sinta-se à } \\
\text { vontade para revelar informações } \\
\text { confidenciais. A divulgação dessas } \\
\text { informações reveladas em segredo } \\
\text { implica uma quebra na relação de } \\
\text { confiança entre o(a) participante o(a) } \\
\text { pesquisador(a). Ainda, a revelação } \\
\text { dessas informações pode prejudicar } \\
\text { o(a) participante. A confidencialidade } \\
\text { representa um aspecto da ética na } \\
\text { pesquisa. }\end{array}$ & $\begin{array}{l}\text { Define a pesquisa como } \\
\text { 'trampolim' para produzir ou } \\
\text { incentivar a transformação social, } \\
\text { especificamente entre grupos } \\
\text { oprimidos. A agenciação pode } \\
\text { significar a revelação de dados } \\
\text { confidenciais com o intuito de gerar } \\
\text { a transformação. A agenciação está } \\
\text { ligada à transparência na pesquisa. } \\
\text { Dessa forma, representa uma } \\
\text { outra perspectiva sobre a ética na } \\
\text { pesquisa. }\end{array}$ \\
\hline
\end{tabular}

Após ter voltado do trabalho de campo em São Paulo, continuei tendo contato com os (as) imigrantes sem documentos por e-mail. Escrevem-me como amigos: como pode ser quebrada a confiança conquistada? E até que ponto posso manter a confidencialidade? Será que a confidencialidade pode significar a não-revelação de dados mais precisos? A confidencialidade preserva a ética na interação com os(as) participantes, mas será que não mina a agenciação ou a própria posição da pesquisa? Em uma pesquisa engajada com a transformação social, voltada para debater a desigualdade, o que deve ser 'sacrificado': a agenciação ou a confidencialidade? Ao mesmo tempo, manter a confidencialidade dos(as) participantes indica uma preocupação com a ética. Qual é a dimensão da ética que deve prevalecer: a ética da interação ou a ética da transformação social? É preciso questionar a confidencialidade à luz da resistência e da agenciação. Trata-se de assumir riscos, em outras palavras, de ser transparente.

Desse modo, a ética não se restringe à confidencialidade, significa a construção de um vínculo entre elementos contraditórios: transparência ou re- 
velação em relação à confidencialidade. Ou seja, a ética significa um processo de tomada de decisões em que se deve decidir entre a quebra de confidências em benefício da transformação social para os(as) próprios participantes da pesquisa. Nesse sentido, o(a) pesquisador(a) não é um participante passivo, porém, ativo na pesquisa, tida como questionadora de relações de poder.

Por fim, uma discussão da ética revela que não existe uma relação binária entre o(a) pesquisador(a) e o(a) participante, ou entre o(a) pesquisador(a) e o campo: a demarcação de limites está ofuscada por identidades ambíguas que pressupõem subjetividades contrárias embutidas no pensamento binário e ocidental. "Isso desafia os pressupostos de subjetividades opostas no Ocidente, o pensamento binário" (Sherif, 2001: 438). Assim, a relação entre a ética e a etnografia é um assunto complexo, que não pode ser resumido nem resolvido de uma forma simples. Mesmo assim, devo destacar que apesar do dilema criado com essas questões, o papel do(a) pesquisador(a) é de ser criticamente engajado(a), de construir uma etnografia em que se problematizem as questões sociais, pois a etnografia não deve ser um processo de estetizar as vozes do campo ou de reforçar as relações de poder existentes, mas de engendrar a transformação social.

\section{CONCLUSÃo}

O desenvolvimento da pesquisa evidencia que a etnografia existe em rede: um contato desencadeia o outro. Além disso, a etnografia revela que o discurso opera em uma cadeia de contextos interligados e estruturados com base em questões de poder e hierarquias. Ao mesmo tempo, a etnografia ressalta a preocupação com questões éticas, destacando nitidamente a dicotomia entre os grupos em foco: subjacente à confidencialidade, na troca dos nomes reais está o poder: o prestígio de pertencer a uma instituição dominante ou o medo de ser perseguido(a) por esse grupo dominante. E, por fim, a própria intersubjetividade da pesquisadora sugere a complexidade e os dilemas de realizar a etnografia, não apenas como metodologia, mas como um engajamento com o outro. Esse engajamento não deve ser apenas uma descrição do discurso da imigração e das relações sociais desse discurso; porém, deve questionar como os participantes se representam e são representados(as) em discursos de poder. 


\section{ReferênCIAS BIBLIOGRÁficAS}

Adams, L. The mascot researcher. Identity, power and knowledge in fieldwork. Journal of Contemporary Ethnography, 28 (4): 331-363, 1999.

Baez, B. Confidentiality in qualitative research. Reflections on secrets, power and agency. Qualitative Research, 2 (1): 35-38, 2002.

Bauman, Z. Comunidade. Trad. P. Dentzien. Rio de Janeiro: Jorge Zahar Editor, 2003.

Berger, L. Inside out. Narrative ethnography as a path toward report. Qualitative Inquiry, 7 (4): 504-518, 2001.

Bhabha, H. The location of culture. Londres, Nova York: Routledge, 1994.

Cameron, D.; Frazer, E.; Harvey, P.; Rampton, B.; Richardson, K. Power/Knowledge. The politics of social science. In: Jaworski, A.; Coupland, N. The discourse reader. Londres, Nova York: Routledge, 1999, pp. 141-57.

Chouliaraki, L. Writing up a classroom ethnography. Issues on interpretation and representation in ethnographic narratives. Working Paper Series of the Lancaster Centre for Language in Social Life, 1994. 71,2005 .

. Media discourse and the public sphere. D.E.L.T.A., 21: Especial: 45-

Chouliaraki, L.; Fairclough, N. Discourse in late modernity. Rethinking critical discourse analysis. Edimburgo: Edinburgh University Press, 1999.

Dimitriadis, G. Coming clean at the hyphen. Ethics and dialogue at a local community center. Qualitative Inquiry, 7 (5): 578-597, 2001.

Drury, J. Cognitive science and hermeneutic explanation. Symbiotic or incompatible frameworks? Philosophy, Psychiatry and Psychology, 1: 40-50,1994.

Drury, J.; Stott, C. Bias as a research strategy in participant observation. The case of intergroup conflict. Field Methods, 13 (1): 47-67, 2001.

Fairclough, N. Researching discourse. Textual analysis for social research. Londres, Nova York: Routledge, 2003.

Giddens, A. A terceira via. Trad. M. L. Borges. Rio de Janeiro, São Paulo: Record, 2001.

Gieve, S.; Magalhães, I. On empowerment. In: Gieve, S. \& Magalhães, I. (Orgs.). Power, ethics and validity. Issues in the relationship between re- 
searcher and researched. Centre for Research in Language Education, Crile Occasional Report, 6. Lancaster University, 1994 (1998).

Habermas, J. A inclusão do outro. Trad. G. Sperber; P. A. Soethe; M. C. Mota. São Paulo: Loyola, 2002.

Henry, G. 'Where are you really from'? Representation, identity and power in the fieldwork experience of a South Asian diasporic. Qualitative Research, 3 (2): 229-242, 2003.

Josselson, R.; Lieblich, A. (Orgs.) The narrative study of lives. Vol. 1. Newbury Park, Londres, Nova Délhi: Sage Publications, 1993.

Leif, C. G; Cytrynbaum, J. D. Illuminating spaces. Relational spaces, complicity, and multisited ethnography. Field Methods, 15 (3): 252-270, 2003.

Nilan, P. 'Dangerous fieldwork' re- examined. The question of researcher subject position. Qualitative Research, 2 (3) : 363 - 386, 2002.

Roberts, C. Professional gatekeeping in intercultural encounters. In: Sarangi, S. \& Coulthard, M. (Orgs.) Discourse and social life. Pearson Education, 2000: 102-119.

Sherif, B. The ambiguity of boundaries in the fieldwork experience. Establishing rapport and negotiating insider and outsider status. Qualitative Inquiry, 7 (4): 436-447, 2001.

Springwood, F. C.; King, R. C. Unsettling engagements. On the ends of rapport in critical ethnography. Qualitative Inquiry, 7 (4): 403-417, 2001.

Thomas, J. Doing critical ethnography. Newbury Park, Londres, Nova Délhi: Sage Publications, 1993.

Van Maanen, J. Tales of the field. On writing ethnography. Chicago, Londres: The University of Chicago Press, 1988.

Doutora em Lingüística, professora do Departamento de Línguas Estrangeiras e tradução da Universidade de Brasília e Coordenadora do Nelis/Ceam dessa mesma instituição.

rachael@unb.br 